This item was submitted to Loughborough's Research Repository by the author.

Items in Figshare are protected by copyright, with all rights reserved, unless otherwise indicated.

\title{
Daily probiotic's (lactobacillus casei shirota) reduction of infection incidence in athletes
}

PLEASE CITE THE PUBLISHED VERSION

PUBLISHER

(C) Human Kinetics, for the International Society of Sport Nutrition

\section{VERSION}

VoR (Version of Record)

LICENCE

CC BY-NC-ND 4.0

\section{REPOSITORY RECORD}

Gleeson, Michael, Nicolette Bishop, Marta Oliveira, and Pedro Tauler. 2019. "Daily Probiotic's (lactobacillus Casei Shirota) Reduction of Infection Incidence in Athletes”. figshare. https://hdl.handle.net/2134/10571. 
This item was submitted to Loughborough's Institutional Repository (https://dspace.lboro.ac.uk/) by the author and is made available under the following Creative Commons Licence conditions.

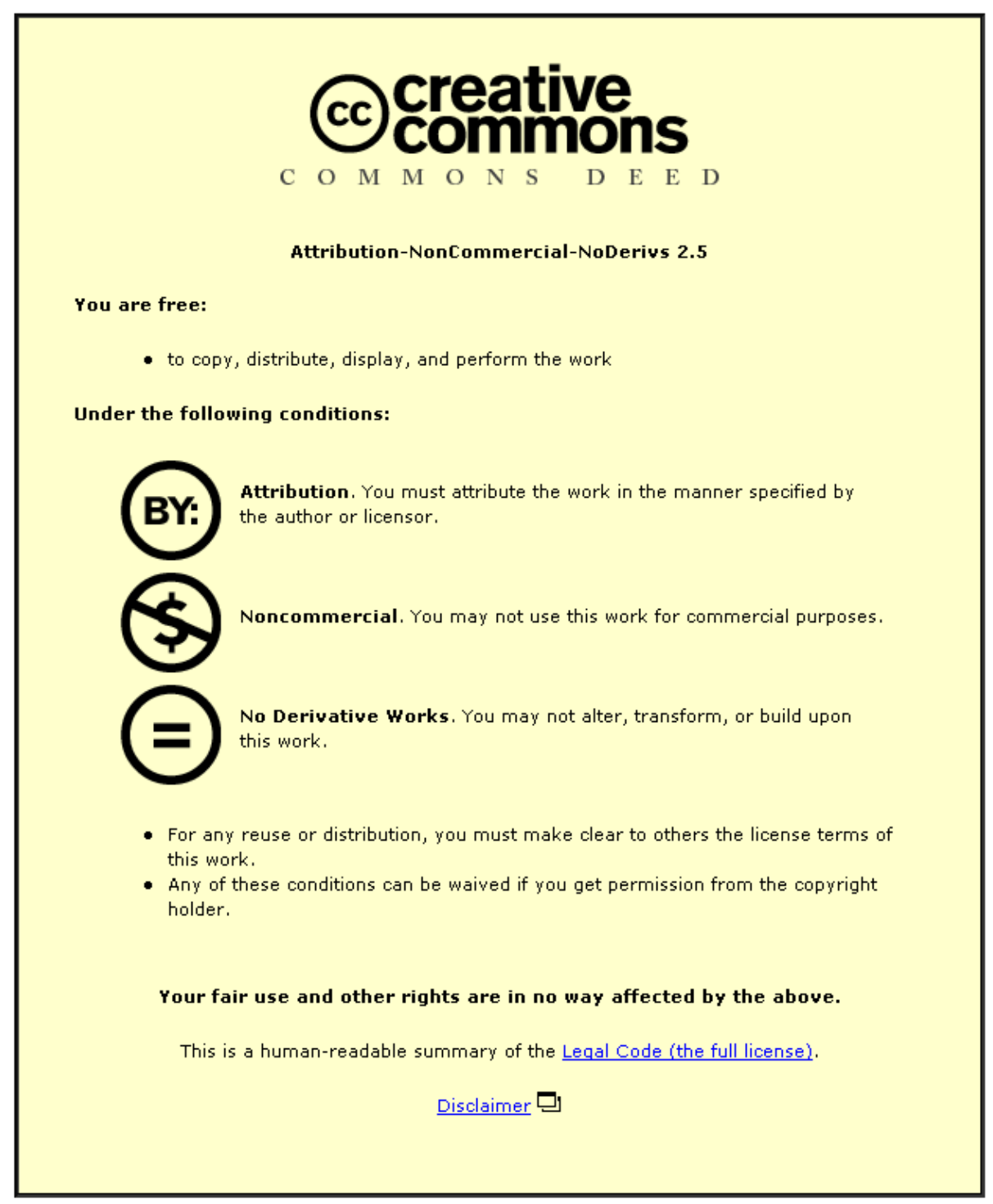

For the full text of this licence, please go to: http://creativecommons.org/licenses/by-nc-nd/2.5/ 


\title{
Daily Probiotic's (Lactobacillus casei Shirota) Reduction of Infection Incidence in Athletes
}

\author{
Michael Gleeson, Nicolette C. Bishop, Marta Oliveira, and Pedro Tauler
}

\begin{abstract}
The purpose of this study was to examine the effects of a probiotic supplement during 4 mo of winter training in men and women engaged in endurance-based physical activities on incidence of upper respiratory-tract infections (URTIs) and immune markers. Eighty-four highly active individuals were randomized to probiotic $(n=42)$ or placebo $(n=42)$ groups and, under double-blind procedures, received probiotic (PRO: Lactobacillus casei Shirota $[\mathrm{LcS}]$ ) or placebo (PLA) daily for $16 \mathrm{wk}$. Resting blood and saliva samples were collected at baseline and after 8 and $16 \mathrm{wk}$. Weekly training and illness logs were kept. Fifty-eight subjects completed the study ( $n=32$ PRO, $n=26$ PLA). The proportion of subjects on PLA who experienced 1 or more weeks with URTI symptoms was $36 \%$ higher than those on PRO (PLA 0.90, PRO 0.66; $p=.021$ ). The number of URTI episodes was significantly higher $(p<.01)$ in the PLA group $(2.1 \pm 1.2)$ than in the PRO group $(1.2$ \pm 1.0 ). Severity and duration of symptoms were not significantly different between treatments. Saliva IgA concentration was higher on PRO than PLA, significant treatment effect $F(1,54)=5.1, p=.03$; this difference was not evident at baseline but was significant after 8 and $16 \mathrm{wk}$ of supplementation. Regular ingestion of $\mathrm{LcS}$ appears to be beneficial in reducing the frequency of URTI in an athletic cohort, which may be related to better maintenance of saliva IgA levels during a winter period of training and competition.
\end{abstract}

Keywords: exercise training, mucosal immunity, leukocytes, respiratory illness, gut microbiota

Probiotics are food supplements that contain live microorganisms that, when administered in adequate amounts, confer a health benefit on the host. There is now a reasonable body of evidence that regular consumption of probiotics can modify the population of the gut microbiota and influence immune function (Borchers, Selmi, Meyers, Keen, \& Gershwin, 2009; Gill \& Cross, 2002; Matsuzaki, 1998; Mengheri, 2008; Minocha, 2009), although it should be noted that such effects are strain specific. Some studies suggest that increased resistance to enteric pathogens and promotion of antitumor activity occur with probiotic supplementation, and there is emerging evidence that probiotics may be effective in alleviating some allergic and respiratory disorders in children (Hatakka et al., 2001; Kopp-Hoolihan, 2001). Furthermore, it has been reported that probiotic supplementation enhances host resistance to upper respiratory-tract infection (URTI) in the general population (de Vrese et al., 2006).

It might be expected that potential benefits of probiotics for human health, in particular reducing infection incidence, are likely to be greater in individuals with decreased immune function or known susceptibility to

Gleeson, Bishop, and Oliveira are with the School of Sport, Exercise and Health Sciences, Loughborough University, Loughborough, UK. Tauler is with the Dept. of Fundamental Biology and Health Sciences, University of the Balearic Islands, Palma de Mallorca, Spain. common infections, such as HIV patients and the elderly. There is currently a lack of information on the effects of probiotics in a healthy but marginally immunocompromised human population. Prolonged intense exercise has been associated with a transient depression of immune function (Gleeson, 2005, 2007), and a heavy training and competition schedule can lead to immune impairment in athletes. This is associated with an increased susceptibility to URTI (Bishop, 2005; Fahlman \& Engels, 2005; Gleeson et al., 1999; Nieman, Johanssen, Lee, \& Arabatzis, 1990; Peters \& Bateman, 1983). Probiotic intake might help reduce the incidence of infection in athletes by improving immune function; there is some limited evidence to support this (West, Pyne, Peake, \& Cripps, 2009). A substantial proportion of runners and triathletes also report gastrointestinal (GI) problems (e.g., abdominal discomfort, diarrhea) during long-distance training runs or competitive events (Simons \& Kennedy, 2004). Probiotics could possibly have a beneficial effect in preventing such symptoms in these individuals by improving gut-barrier function (Collado, Isolauri, Salminen, \& Sanz, 2009; Kekkonen et al., 2007; Mengheri, 2008).

To date, there are very few published studies on the effectiveness of probiotic use in athletes. Cox, Pyne, Saunders, and Fricker (2010) showed that during the winter months athletes $(N=20)$ suffered fewer days of respiratory illness and lower severity of respiratoryillness symptoms when taking a daily probiotic (Lactobacillus fermentum). However, that study had a small 
number of subjects, and illness symptoms were only recorded over a 4-week period.

The aims of the current study were to examine the effects of 4 months of daily oral supplementation with a commercially available fermented milk drink containing the gram-positive probiotic L. casei Shirota $(\mathrm{LcS})$ on infection incidence and selected markers of immune function in a cohort of university-based endurance athletes during a period of winter training and competition. We chose to examine this particular probiotic because it is one of the most popular commercially available probiotics available worldwide, and there is strong evidence that the bacteria it contains survive GI transit, modify the gut microbiota population (Matsumoto et al., 2006; Spanhaak, Havenaar, \& Schaafsma, 1998), and can alter some aspects of systemic immunity in humans (Matsuzaki, 1998; Nagao, Nakayama, Muto, \& Okumura, 2000; O’Connell, Allgrove, Pollard, Xiang, \& Harbige, 2010).

\section{Methods}

\section{Subjects}

Eighty-four healthy subjects who were engaged in regular sports training (predominantly endurance-based activities such as running, cycling, swimming, triathlon, team games, and racquet sports) volunteered to participate in the study. They ranged from recreationally active to Olympic triathletes, and their self-reported training loads averaged $10 \mathrm{hr} /$ week. Subjects were required to complete a comprehensive health-screening questionnaire before starting the study and to not have taken any medication in the 4 weeks before the study. All subjects recruited to the study confirmed that they had not taken any probiotic in the previous 4 months. All subjects were fully informed about the rationale for the study and of all experimental procedures to be undertaken. Subjects provided written consent to participate in the study, which had earlier received the approval of Loughborough University's ethical advisory committee. Subjects were enrolled after having fulfilled all inclusion criteria and presenting none of the exclusion criteria (determined by both questionnaire and interview).

Subjects could be included if they were currently healthy, had been involved in endurance training for at least 2 years, engaged in at least three sessions and at least $3 \mathrm{hr}$ of moderate- to high-intensity training time per week, and were 18-55 years of age. Subjects presenting one or more of the following criteria were excluded from participation: smoking or use of any medication; currently taking probiotic supplements; suffered from or had a history of cardiac, hepatic, renal, pulmonary, neurological, GI, hematological, or psychiatric illness; objected to the prescription of diet (abstinence from fermented milk products other than the daily supplement).

A total of 84 healthy individuals were recruited as subjects and were randomly assigned to one of two treatments with stratification by gender only; under doubleblind procedures 42 subjects received the probiotic and
42 received the placebo. Of these 84 subjects, 30 were female and 54 were male, with a mean age at recruitment of $27.0 \pm 11.6$ years $(M \pm S D)$. Sample-size estimation of 32 subjects per treatment group was based on an expected rate of $2.0 \pm 1.0$ URTI episodes $(M \pm S D)$ during the winter months (Neville, Gleeson, \& Folland, 2008), a target $30 \%$ reduction in number of episodes, statistical power of $80 \%$, and a Type I error of $5 \%$. We initially recruited 84 volunteers to account for an estimated $30 \%$ dropout rate over the study period.

\section{First Visit}

For the first visit to the laboratory, subjects arrived in the morning at 8:30-10:30 a.m. after an overnight fast of approximately $12 \mathrm{hr}$. They were asked to empty their bladder before body mass and height were recorded. Information about the study was given to them, and they then signed an informed-consent form. They then sat quietly for $10 \mathrm{~min}$ and completed a health-screen questionnaire and inclusion- and exclusion-criteria questionnaire before providing an unstimulated saliva sample by passive dribble into a sterile collection tube. Saliva samples were stored frozen at $-80{ }^{\circ} \mathrm{C}$ before analysis. Subsequently, a resting venous blood sample $(11 \mathrm{ml})$ was obtained by venipuncture from an antecubital forearm vein into two Vacutainer tubes (Becton Dickinson, Oxford, UK) containing either $\mathrm{K}_{3}$ EDTA or heparin. Hematological analysis was immediately carried out on the EDTA sample (including hemoglobin, hematocrit, and total and differential leukocyte counts) using an automated cell counter ( $\mathrm{A}^{\mathrm{c}}$.T5diff hematology analyzer, Beckman Coulter, High Wycombe, UK). Provided that subjects met the criteria for inclusion in the study, they were randomly assigned to the treatment or placebo group and asked to start taking the supplement the next day.

\section{Study Intervention}

Probiotic and placebo supplements were supplied as fermented milk in sealed pots of $65 \mathrm{ml}$ with date-stamped expiration. The probiotic drink contained a minimum of $6.5 \times 10^{9}$ live cells of $\mathrm{LcS}$ in each pot. The placebo was identical in taste and color to the probiotic but contained no LcS. The supplements were stored at $4-7^{\circ} \mathrm{C}$ (domestic refrigerator). Subjects returned to the laboratory every 2-3 weeks to receive a fresh supply of supplement. A compliance log of sample collection was taken. Subjects consumed the supplement twice per day, one 65-ml pot taken with breakfast and one with the evening meal, for 16 weeks. They were asked to keep a record of any days when they missed taking the supplement.

\section{Study Protocol}

During the 4-month intervention period subjects were asked to continue with their normal training programs. Consumption of supplements (vitamins and minerals, etc.), additional probiotics, or any fermented dairy products (e.g., yogurt, sour cream, crème fraiche) was 
not permitted during this period. Subjects completed a health questionnaire (URTI symptoms and GI-discomfort symptoms) on a weekly basis. They were not required to abstain from medication when they were suffering from illness symptoms, but they were required, on a weekly basis, to report any unprescribed medications taken, visits to the doctor, and any prescribed medications.

The illness symptoms listed on the questionnaire were sore throat, inflammation in the throat, runny nose, cough, repetitive sneezing, fever, persistent muscle soreness, joint aches and pains, weakness, headache, and loss of sleep. The nonnumerical ratings of light, moderate, and severe (L, M, or S, respectively) were scored as 1 , 2 , and 3 , respectively, to provide a quantitative means of data analysis (Fricker et al., 2005), and the total symptom score for every subject each week was calculated by multiplying the total number of days each symptom was experienced by the numerical ratings of $\mathrm{L}, \mathrm{M}$, or $\mathrm{S}$ symptoms of 1, 2 or 3, respectively. In any given week a total symptom score $\geq 12$ was taken to indicate that a URTI was present. This score was chosen because to achieve it a subject would have to record at least three moderate symptoms lasting for 2 days or two moderate symptoms lasting for at least 3 days in a given week. A single URTI episode was defined as a period during which the weekly total symptom score was $\geq 12$ and separated by at least 1 week from another week with a total symptom score $\geq 12$. Subjects were also asked to rate the impact of illness symptoms on their ability to train (normal training maintained, training reduced, or training discontinued; $\mathrm{L}, \mathrm{M}$, or S, respectively).

The GI-discomfort symptoms listed on the questionnaire were loss of appetite, stomach upset, vomiting, abdominal pain, and diarrhea. These symptoms were rated and scored the same way as the illness symptoms. Subjects were also asked to fill in a standard short-form International Physical Activity Questionnaire (http:// www.ipaq.ki.se/downloads.htm) at weekly intervals, thus providing quantitative information on training loads in metabolic-equivalent (MET) hr/week (Craig et al., 2003).

After 8 and 16 weeks subjects came to the laboratory again after an overnight fast. They were required to abstain from any strenuous physical activity for $24 \mathrm{hr}$ before coming to the laboratory. During these visits body mass was recorded and an unstimulated saliva sample and venous blood samples were collected as described for the first visit to the laboratory.

\section{Blood Cell Counts}

Blood samples in the $\mathrm{K}_{3}$ EDTA Vacutainer $(4 \mathrm{ml})$ were used for hematological analysis using an automated cell counter ( $\mathrm{A}^{\mathrm{c}}$.T5diff hematology analyzer, Beckman Coulter, High Wycombe, UK). The intra-assay coefficient of variation for all measured variables was less than $3.0 \%$.

\section{Plasma Immunoglobulins}

The remaining blood in the $\mathrm{K}_{3}$ EDTA tube was centrifuged at $1,500 \mathrm{~g}$ for $10 \mathrm{~min}$ at $4{ }^{\circ} \mathrm{C}$ within $10 \mathrm{~min}$ of sampling. The plasma obtained was immediately stored at $-80^{\circ} \mathrm{C}$ before analysis of immunoglobulins $\mathrm{A}, \mathrm{G}$, and $\mathrm{M}$ (immunoturbidometric assay on Pentra 400 autoanalyzer, Horiba, France, using the manufacturer's calibrators and controls). The intra-assay coefficients of variation for immunoglobulins $\mathrm{A}, \mathrm{G}$, and $\mathrm{M}$ were $3.2 \%, 1.9 \%$, and $2.3 \%$, respectively.

\section{Lymphocyte Subsets}

Lymphocyte subsets CD3, CD4, CD8, CD19, and CD56 to enumerate total $\mathrm{T}$ cells, T-helper cells, T-cytotoxic cells, B cells, and NK cells, respectively, were determined by three-color flow cytometry (Becton Dickinson FACSCalibur) with CellQuest software (Becton Dickinson Biosciences, Oxford, UK) as described previously (Lancaster et al., 2004). Forward-scatter versus side-scatter plots were used to gate on the lymphocyte population by morphology, and 10,000 lymphocyte events were acquired per analysis. Estimations of the absolute $\mathrm{CD}^{+}$, $\mathrm{CD} 3+\mathrm{CD}^{+}, \mathrm{CD} 3+\mathrm{CD}^{+}, \mathrm{NK}$ cell (CD3-CD56+), and $\mathrm{B}$ cell (CD3-CD19+) numbers were derived from the total lymphocyte count.

\section{Antigen-Stimulated Cytokine Production}

Stimulated whole-blood-culture production of cytokines (interferon [IFN]- $\gamma$, tumor-necrosis factor- $\alpha$, interleukin [IL]-1 $\beta$, IL-2, IL-4, IL-6, IL-8, IL-10, and macrophage chemoattractant protein-1) was determined as follows: $2 \mathrm{ml}$ of heparinized whole blood were added to $2 \mathrm{ml}$ of RPMI medium (Sigma Chemicals, Poole, UK) with added stimulant at a dilution of 1:4,000. The stimulant was a commercially available multiantigen vaccine (Pediacel Vaccine, Sanofi Pasteur, UK) containing diphtheria, tetanus, acellular pertussis, poliomyelitis, and hemophilus influenzae Type b antigens. Whole blood was cultured at $37{ }^{\circ} \mathrm{C}$ and $5 \% \mathrm{CO}_{2}$ for $24 \mathrm{hr}$. After centrifugation at $1,500 \mathrm{~g}$ for $10 \mathrm{~min}$ at $4{ }^{\circ} \mathrm{C}$, supernatants were collected and stored frozen at $-80{ }^{\circ} \mathrm{C}$ before analysis of cytokine concentrations using an Evidence Investigator System and the cytokine biochip array EV3513 (Randox, County Antrim, UK).

\section{Saliva IgA}

Duplicate saliva samples were analyzed for secretory $\operatorname{IgA}$ using an ELISA kit (Salimetrics, Philadelphia, PA). The intra-assay coefficient of variation for $\operatorname{IgA}$ was $10.1 \%$.

\section{Statistical Analysis}

The difference in proportion of subjects who presented with symptoms of infection during the trial between the probiotic and placebo groups was assessed by chi-square test. Comparisons of the proportion of days or weeks with infection symptoms were also assessed with a chi-square test. For the total symptom-severity score and the mean duration of infection symptoms of subjects with infection symptoms, comparisons between the treatments for single 
measurements were made using independent (unpaired) $t$ tests. Changes in saliva and blood variables during the study were analyzed using a two-factor (Treatment $x$ Time) between- and within-subjects ANOVA with repeated measures (time: 0,8 , and 16 weeks of intervention). Corresponding assumptions of homogeneity of variances and intercorrelation were checked, as was sphericity in the data. Any significant $F$ ratios subsequently shown were assessed using Student's paired $t$ tests with Holm-Bonferroni correction for multiple comparisons applied to the unadjusted $p$ value. The observed powers of the reported main and interaction effects were all greater than .8. Partial etasquared values were assessed to estimate the effect size of any statistically significant differences found. Using guidelines of Cohen (1988), $.01=$ small effect, $.06=$ moderate effect, and $.14=$ large effect. Statistical significance was accepted at $p<.05$. Data are expressed as $M \pm S D$.

\section{Results}

\section{Adherence to the Study}

Of the 84 subjects, 65 successfully completed 8 weeks of the study and 58 subjects completed the full 16 weeks. Several subjects withdrew because they could not take the liquid supplement with them to competitions to which they had to travel by air. Others withdrew because of injury or persistent illness (preventing them from performing training) or for undisclosed reasons. Adherence to the intervention was good: Subjects who completed the study reported that they missed taking the supplement on average only on 3 days (range 0-12 days). Saliva and blood samples were obtained on all three visits from 53 subjects, although sufficient blood volume to allow analyses of all variables was only obtained from 49 subjects. Subjects were asked at the end of the study which treatment they thought they were on. Sixty percent said they did not know, $23 \%$ thought they were on probiotic, and $17 \%$ thought they had taken placebo. Of the subjects who expressed an opinion, $43 \%$ were correct in their selection of treatment and $57 \%$ were incorrect. Hence, the study blinding was effective.

The baseline characteristics of the probiotic subjects $(n=32)$ who completed the study were as follows: age 32 \pm 14 years, body mass $71.2 \pm 9.9 \mathrm{~kg}$, height $175 \pm 9 \mathrm{~cm}$, body-mass index $23.2 \pm 2.8 \mathrm{~kg} / \mathrm{m}^{2}$, and self-reported weekly training load $8.7 \pm 4.1 \mathrm{hr} /$ week. The baseline characteristics of the placebo subjects $(n=26)$ were as follows: age $25 \pm 9$ years, body mass $71.6 \pm 10.7 \mathrm{~kg}$, height $175 \pm 8 \mathrm{~cm}$, body-mass index $23.3 \pm 2.5 \mathrm{~kg} / \mathrm{m}^{2}$, and self-reported weekly training load $9.3 \pm 3.8 \mathrm{hr} /$ week. There were no statistically significant differences between the two treatment groups.

\section{Training Loads}

Analysis of the International Physical Activity Questionnaire indicated that the weekly training loads were relatively stable between and within experimental groups over the 16 weeks of the study (Figure 1) and that the means were not significantly different for the probiotic and placebo groups: $62.6 \pm 32.2$ and $62.6 \pm 32.6 \mathrm{MET}-\mathrm{hr} /$ week, respectively $(p=.784)$. This is equivalent to about $10 \mathrm{hr}$ of moderate to vigorous activity per week.

\section{Infection-Symptom Incidence}

Analysis of the URTI-symptom questionnaires indicated that $18 \pm 7 \%$ of the cohort experienced a URTI episode each week. Fifteen subjects did not experience a single URTI episode during the study period, and 50 subjects experienced at least one. The proportion of subjects on placebo who experienced one or more weeks with URTI symptoms was higher than that of those on probiotic (placebo .90 , probiotic $.66 ; p=.021$ ). The proportion of weeks that subjects suffered URTI symptoms was

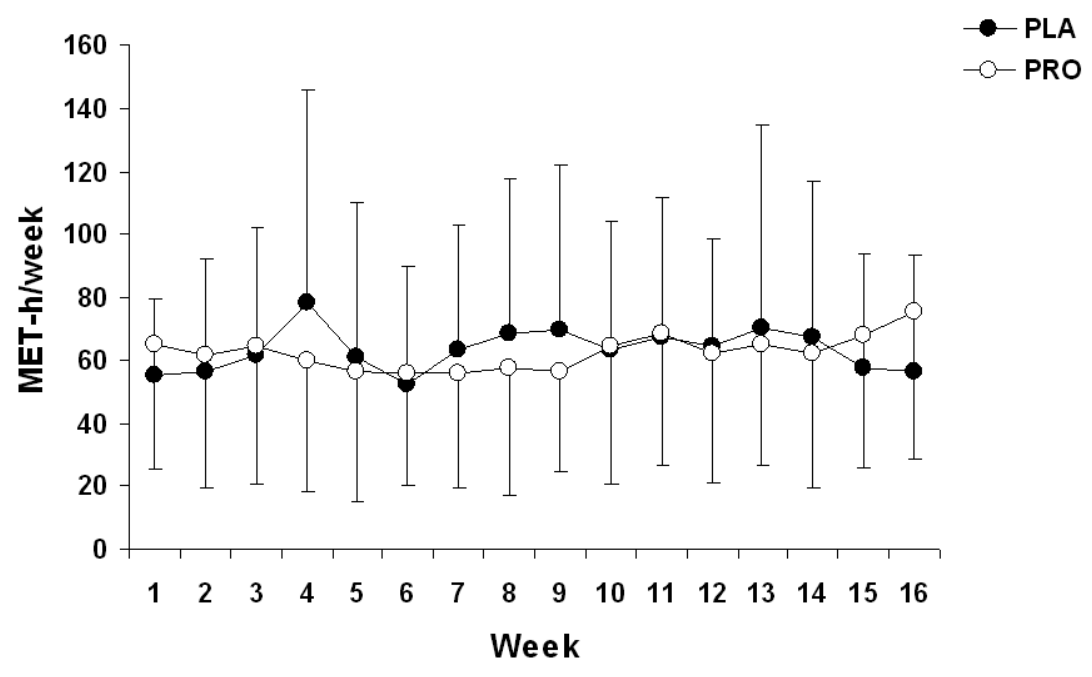

Figure 1 - Training loads in metabolic-equivalent (MET) hr/week over the 16-week study period for subjects who completed the study, $M \pm S D$. PLA = placebo; $\mathrm{PRO}=$ probiotic. No statistically significant difference between treatments. 
significantly higher in the placebo group than in the probiotic group (.23 and .12 , respectively; $p<.001)$. Furthermore, the proportion of weeks that subjects took medication was also significantly higher in the placebo group than in the probiotic group (.17 and .10 , respectively; $p<.01)$.

The mean number of URTI-symptom weeks (probiotic $1.9 \pm 1.5$, placebo $3.5 \pm 2.0 ; p<.01)$ and the mean number of URTI episodes (probiotic 1.2 \pm 1.0 , placebo $2.1 \pm 1.2 ; p<.01$ ) were $\sim 50 \%$ lower on probiotic than placebo.

\section{Severity and Mean Duration of URTI Symptoms}

When a URTI episode was present, the mean total symptom-severity score (probiotic $49 \pm 55$, placebo 50 $\pm 32 ; p=.928$ ) and duration of symptoms (probiotic 7.9 \pm 5.5 days, placebo $7.6 \pm 3.2$ days; $p=.801$ ) were not significantly different between treatments. However, the proportion of subjects who stated that training was negatively affected when they suffered URTI symptoms was lower on probiotic than on placebo (.54 and .81, respectively; $p=.036$ ). When a URTI episode was present, the proportion of subjects who took medication was similar in the probiotic and placebo groups (.74 and .78, respectively), and the proportion of subjects who visited their doctor was also similar in the probiotic and placebo groups (.26 and .19 , respectively).

\section{Incidence of GI-Discomfort Symptoms}

The proportion of subjects on placebo who experienced 1 or more weeks with GI-discomfort symptoms was not significantly different than for those on probiotic (.57 and .54 , respectively). However, the proportion of days that subjects suffered GI-discomfort symptoms, though low in both groups, was $33 \%$ higher in the placebo group than in the probiotic group (.03 and .02 , respectively; $p=$ .008). During weeks when one or more GI-discomfort symptoms were present, the mean total symptom-severity score (probiotic $9 \pm 4$, placebo $12 \pm 4 ; p=.444$ ) and duration of symptoms (probiotic $4.2 \pm 3.8$ days, placebo $5.9 \pm 3.9$ days; $p=.410$ ) were not significantly different between treatments.

\section{Plasma and Saliva Immunoglobulins}

There were no significant time, treatment, or interaction effects for plasma concentrations of $\operatorname{IgA}$ and $\operatorname{IgM}$ (Table 1). Although there was significant interaction for plasma $\operatorname{IgG}, F(2,40)=3.9, p=.029, \eta^{2}=.16$, and plasma total $\operatorname{Ig}, F(2,40)=3.4, p=.045, \eta^{2}=.14$, post hoc tests did not reveal significant differences between treatments at any time point. Saliva IgA concentration was higher with probiotic than placebo-main effect for treatment $F(1,54)=5.1, p=.03, \eta^{2}=0.09$; this difference was not evident at baseline but was significant after 8 and 16 weeks of supplementation (Figure 2).

\section{Blood Leukocyte Counts and Lymphocyte Subsets}

There were no significant time, treatment, or interaction effects for blood total or differential leukocyte counts (Table 2), apart from monocyte counts, which were slightly lower with probiotic than placebo-main effect of treatment $F(1,43)=4.2, p=.047, \eta^{2}=.09$. There were no significant time, treatment, or interaction effects for any of the blood lymphocyte subsets (Table 2).

Table 1 Plasma IgA, IgG, IgM, and Total Ig (g/L) Before and After 8 and 16 Weeks of the Intervention Period

\begin{tabular}{|c|c|c|c|c|c|}
\hline & Before & 8 weeks & 16 weeks & $\begin{array}{l}p, \text { interaction, } \\
\text { time, treatment }\end{array}$ & Post hoc \\
\hline IgA & & & & $.241, .098, .095$ & \\
\hline placebo & $1.85(0.97)$ & $0.06(-0.04$ to 0.16$)$ & $-0.05(-0.13$ to 0.03$)$ & & \\
\hline probiotic & $2.30(0.65)$ & $-0.03(-0.10$ to 0.04$)$ & $-0.04(-0.13$ to 0.05$)$ & & \\
\hline IgG & & & & $.029 *, .312, .816$ & $*$ n.s. \\
\hline placebo & $10.9(1.4)$ & $0.6(0.0-1.2)$ & $0.3(-0.1$ to 0.7$)$ & & \\
\hline probiotic & $11.4(2.3)$ & $-0.1(-0.3$ to 0.1$)$ & $0.1(-0.2$ to 0.4$)$ & & \\
\hline $\operatorname{IgM}$ & & & & $.310, .306, .356$ & \\
\hline placebo & $1.23(0.61)$ & $0.03(-0.03$ to 0.09$)$ & $0.01(-0.04$ to 0.06$)$ & & \\
\hline probiotic & $1.10(0.35)$ & $0.03(-0.06-0.12)$ & $-0.03(-0.12$ to 0.06$)$ & & \\
\hline Total Ig & & & & $.045^{*}, .240, .558$ & $*$ n.s. \\
\hline placebo & $14.0(1.9)$ & $0.6(-0.1$ to 0.13$)$ & $0.3(-0.1$ to 0.7$)$ & & \\
\hline probiotic & $14.8(2.6)$ & $-0.1(-0.4$ to 0.2$)$ & $-0.2(-0.6$ to 0.2$)$ & & \\
\hline
\end{tabular}

Note. Baseline values before supplementation are expressed as $M(S D) ; n=25$ probiotic, $n=20$ placebo. The values shown at 8 and 16 weeks of supplementation are the mean change (with $95 \%$ confidence limits) from baseline. These data are from the subjects who completed the study and for whom blood samples were obtained on all three visits. 


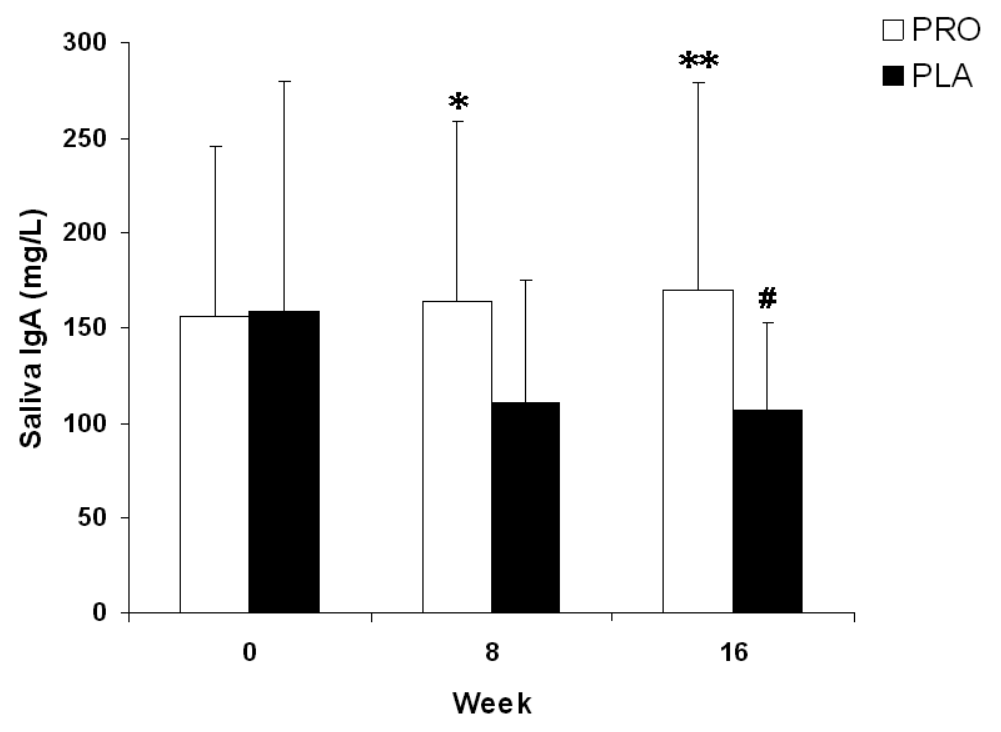

Figure 2 - Saliva IgA concentration before and after 8 and 16 weeks of the study for the subjects who completed the study and for whom saliva samples were obtained on all three visits (PRO $n=32$, PLA $n=24), M \pm S D$. Saliva IgA concentration was higher on PRO than PLA, significant trial effect $F(1,54)=5.1, p=.03$; this difference was not evident at baseline but was significant after 8 and 16 weeks of supplementation $(* p<.05 ; * *<.01)$. PLA $=$ placebo; PRO = probiotic. $\# p<.05$ versus Week 0.

\section{Stimulated Whole-Blood-Culture Cytokine Production}

There were no significant time, treatment, or interaction effects for whole-blood-culture production of IL-10 (Table 3). For all the other cytokines there were no significant interactions or main effects of treatment, but there were significant effects of time, with cytokine production being higher at baseline than at 8 weeks and 16 weeks (IL-2, IL-4, IL-6, IL-8, and tumor-necrosis factor- $\alpha$ ) or only at 16 weeks (IL- $1 \beta$, IFN- $\gamma$, and macrophage chemoattractant protein-1; $p<.01$ for all except IFN- $\gamma$, where $p<.05 ; \eta^{2}>.14$ for all).

\section{Discussion}

The main findings of the current study were that the proportion of subjects who experienced 1 or more weeks with URTI symptoms was $27 \%$ lower and the average number of URTI episodes was 50\% lower in the probiotic group than in the placebo group. The severity and duration of symptoms were not significantly different on probiotic than with placebo, but training was less affected when URTI was present for the probiotic group than the placebo group. These positive clinical consequences provide evidence for the beneficial effects of daily LcS ingestion in a cohort of highly physically active people. The proportion of subjects from the placebo group who experienced 1 or more weeks with GI-discomfort symptoms was not significantly different from the probiotic group, but the proportion of days that subjects suffered these symptoms was 33\% lower with probiotic than placebo, which can be seen as another benefit of this nutritional intervention for an athlete cohort.
Some emerging evidence from recent studies suggests that probiotics can be effective in preventing not only GI infections (Gill \& Prasad, 2008; Minocha, 2009) but also respiratory infections. For example, administration of Lactobacillus $G G$ to children in day care centers decreased the incidence of URTI (Hatakka et al., 2001). In several recent large-scale human studies it has been demonstrated that regular, long-term intake of various probiotic-prebiotic combinations improved health by reducing both the incidence and the severity of respiratory diseases during the winter season (Pregliasco et al., 2008; Winkler, de Vrese, Laue, \& Schrezenmeir, 2005). Other studies have reported that probiotics are associated with shortened duration of common cold symptoms and reduced severity of symptoms without an effect on infection incidence in adults during winter-to-spring periods (de Vrese et al., 2006; Guillemard, Tondu, Lacoin, \& Schrezenmeir, 2009).

There is now substantial evidence that a few months of oral probiotic supplementation can modulate systemic immune functions (de Vrese et al., 2006; Gill \& Prasad, 2008; Kim, Park, Cho, Paik, \& Park, 2006; Miettinen, Vuopio-Varkila, \& Varkila, 1996; Olivares et al., 2006; Winkler et al., 2005). Probiotics influence immunity by interacting with receptors on intestinal epithelial cells, $M$ cells, and dendritic cells in the GI tract and with the common mucosal immune system, an interconnected system that links the Peyer's patches in the GI tract to effector sites on the mucosa in the GI tract and beyond in the upper respiratory and urogenital tracts (Kudsk, 2002). Several studies have demonstrated the ability of regular ingestion of LcS to modulate the healthy human gut microbial population and to induce some immune changes, including 
Table 2 Blood Cell Counts Before and After 8 and 16 Weeks of the Intervention Period

\begin{tabular}{|c|c|c|c|c|c|}
\hline & Before & 8 weeks & 16 weeks & $\begin{array}{l}p \text {, interaction, } \\
\text { time, treatment }\end{array}$ & Post hoc \\
\hline \multicolumn{6}{|l|}{ Leukocytes } \\
\hline Leukocytes $\left(\right.$ cells $\left.\times 10^{9} / \mathrm{L}\right)$ & & & & $.651, .836, .275$ & \\
\hline placebo & $6.1(1.6)$ & $-0.1(-0.9$ to 0.7$)$ & $-0.3(-1.0$ to 0.4$)$ & & \\
\hline probiotic & $5.6(1.4)$ & $-0.1(-0.4$ to 0.6$)$ & $0.1(-0.8$ to 0.9$)$ & & \\
\hline Neutrophils $\left(\right.$ cells $\left.\times 10^{9} / \mathrm{L}\right)$ & & & & $.727, .594, .484$ & \\
\hline placebo & $3.2(1.2)$ & $-0.2(-0.9$ to 0.5$)$ & $-0.2(-0.9$ to 0.5$)$ & & \\
\hline probiotic & $2.8(1.3)$ & $-0.1(-0.4$ to 0.6$)$ & $0.2(-0.7$ to 1.1$)$ & & \\
\hline Monocytes $\left(\right.$ cells $\left.\times 10^{9} / \mathrm{L}\right)$ & & & & $.480, .144, .047^{*}$ & $\begin{array}{l}* \text { probiotic } \\
<\text { placebo }\end{array}$ \\
\hline placebo & $0.48(0.18)$ & $0.07(-0.03$ to 0.17$)$ & $0.06(-0.04$ to 0.16$)$ & & \\
\hline probiotic & $0.44(0.15)$ & $0.00(-0.05$ to 0.05$)$ & $0.01(-0.05$ to 0.07$)$ & & \\
\hline Lymphocytes $\left(\right.$ cells $\left.\times 10^{9} / \mathrm{L}\right)$ & & & & $.957, .057, .576$ & \\
\hline placebo & $2.00(0.72)$ & $0.17(-0.03$ to 0.38$)$ & $0.07(-0.22$ to 0.32$)$ & & \\
\hline probiotic & $1.92(0.50)$ & $0.14(-0.01$ to 0.29$)$ & $0.07(-0.12$ to 0.26$)$ & & \\
\hline \multicolumn{6}{|l|}{ Lymphocyte Subsets } \\
\hline $\mathrm{T}$ cells $\mathrm{CD} 3+\left(\right.$ cells $\left.\times 10^{9} / \mathrm{L}\right)$ & & & & $.889, .138, .656$ & \\
\hline placebo & $1.23(0.54)$ & $0.09(-0.14$ to 0.32$)$ & $0.00(-0.21$ to 0.21$)$ & & \\
\hline probiotic & $1.17(0.35)$ & $0.12(0.01-0.23)$ & $0.00(-0.14$ to 0.14$)$ & & \\
\hline $\begin{array}{l}\text { T-Helper cells CD3+CD4+ } \\
\left(\text { cells } \times 10^{9} / \mathrm{L}\right)\end{array}$ & & & & $.709, .066, .365$ & \\
\hline placebo & $0.72(0.27)$ & $0.05(-0.04$ to 0.14$)$ & $0.00(-0.12$ to 0.12$)$ & & \\
\hline probiotic & $0.63(0.15)$ & $0.09(0.01-0.17)$ & $0.04(-0.05$ to 0.13$)$ & & \\
\hline $\begin{array}{l}\text { T-cytotoxic cells } \\
\left.\text { CD3+CD8+ (cells } \times 10^{9} / \mathrm{L}\right)\end{array}$ & & & & $.927, .038 *, .910$ & $*$ n.s. \\
\hline placebo & $0.45(0.27)$ & $0.09(-0.03$ to 0.21$)$ & $0.01(-0.07$ to 0.09$)$ & & \\
\hline robiotic & $0.45(0.25)$ & $0.07(0.0-0.14)$ & $0.01(-0.08$ to 0.10$)$ & & \\
\hline $\begin{array}{l}\text { B cells CD3-CD19+ } \\
\text { (cells x 109/L) }\end{array}$ & & & & $.130, .742, .932$ & \\
\hline placebo & $0.24(0.13)$ & $-0.02(-0.04$ to 0.0$)$ & $-0.02(-0.06$ to 0.2$)$ & & \\
\hline probiotic & $0.21(0.10)$ & $0.03(0.01-0.05)$ & $0.02(0.00-0.04)$ & & \\
\hline $\begin{array}{l}\text { Natural killer cells CD3- } \\
\left.\text { CD56+ (cells } \times 10^{9} / \mathrm{L}\right)\end{array}$ & & & & $.354, .076, .432$ & \\
\hline placebo & $0.23(0.17)$ & $0.04(-0.02$ to 0.10$)$ & $0.01(-0.03$ to 0.05$)$ & & \\
\hline probiotic & $0.23(0.14)$ & $-0.01(-0.06$ to 0.04$)$ & $-0.03(-0.07$ to 0.01$)$ & & \\
\hline
\end{tabular}

Note. Baseline values before supplementation are expressed as $M(S D) ; n=25$ probiotic, $n=20$ placebo. The values shown at 8 and 16 weeks of supplementation are the mean change (with $95 \%$ confidence limits) from baseline. These data are from the subjects who completed the study and for whom blood samples were obtained on all three visits.

stimulation of Th1 cellular immune responses and NK cell cytolytic activity (Matsuzaki, 1998; Nagao et al., 2000) and increases in saliva IgA secretion (O'Connell et al., 2010).

Although in the current study regular LcS ingestion was associated with lower URTI incidence, we could not directly attribute this to any specific improvement of immune function, because supplementation with $\mathrm{LcS}$ for 16 weeks did not substantially alter circulating leukocyte, neutrophil, lymphocyte, monocyte, or lymphocyte subset numbers; plasma immunoglobulins; or antigenstimulated whole-blood-culture cytokine production. The data on saliva IgA suggest the possibility that LcS supplementation helped maintain saliva IgA concentration compared with placebo during a period when some aspects of immune function (saliva IgA in the placebo group and antigen-stimulated cytokine production in both groups) were decreased. Note that in both athlete 
Table 3 Stimulated Whole-Blood-Culture Cytokine Production Before and After 8 and 16 Weeks of the Intervention

\begin{tabular}{|c|c|c|c|c|c|}
\hline & Before & 8 weeks & 16 weeks & $\begin{array}{l}p \text {, interaction, } \\
\text { time, treatment }\end{array}$ & Post hoc ${ }^{a}$ \\
\hline \multicolumn{6}{|l|}{ Interleukins } \\
\hline $\mathrm{IL}-1 \beta(\mathrm{pg} / \mathrm{ml})$ & & & & $.673, .001 *, .583$ & $* 1>3, p<.001$ \\
\hline placebo & $9.8(7.8)$ & $-1.0(-6.5$ to 4.5$)$ & $-3.8(-7.9$ to 0.3$)$ & & \\
\hline probiotic & $9.8(8.9)$ & $-3.5(-7.3$ to 0.3$)$ & $-4.5(-6.3$ to 2.7$)$ & & \\
\hline IL-2 (pg/ml) & & & & $.540, .001 *, .166$ & $\begin{array}{l}* 1>2,1>3 \\
\text { both } p<.001\end{array}$ \\
\hline placebo & $167(189)$ & $-72(-114$ to 30$)$ & $-105(-190$ to 20$)$ & & \\
\hline probiotic & $108(127)$ & $-63(-116$ to 10$)$ & $-60(-107$ to 13$)$ & & \\
\hline IL-4 (pg/ml) & & & & $.415, .018^{*}, .305$ & $\begin{array}{c}* 1>2, p<.01 \\
1>3, p<.05125\end{array}$ \\
\hline placebo & $4.0(4.4)$ & $-1.5(-3.2$ to 0.2$)$ & $-1.8(-3.9$ to 0.3$)$ & & \\
\hline probiotic & $2.9(2.4)$ & $-0.9(-1.6$ to 0.2$)$ & $-0.7(-1.4$ to 0.0$)$ & & \\
\hline IL-6 (pg/ml) & & & & $.488, .001 *, .550$ & $\begin{array}{l}* 1>2,1>3 \\
\text { both } p<.01\end{array}$ \\
\hline placebo & $158(126)$ & -35 (-77 to 7$)$ & $-94(-152$ to 35$)$ & & \\
\hline probiotic & $187(130)$ & $-71(-119$ to 23$)$ & $-97(-157$ to 37$)$ & & \\
\hline IL-8 (pg/ml) & & & & $.599, .001 *, .737$ & $\begin{array}{c}* 1>2,1>3 \\
\text { both } p<.01\end{array}$ \\
\hline placebo & $1,193(656)$ & $-372(-629$ to 115$)$ & $-294(-739$ to 151$)$ & & \\
\hline probiotic & $1,355(602)$ & $-473(-786$ to 160$)$ & $-522(-854$ to 190$)$ & & \\
\hline IL-10 (pg/ml) & & & & $.125, .070, .345$ & \\
\hline placebo & $3.6(2.6)$ & $0.6(-1.8$ to 3.0$)$ & $-1.0(-2.3$ to 0.3$)$ & & \\
\hline probiotic & $3.9(4.3)$ & $-2.1(-3.4$ to 0.8$)$ & $-1.5(-3.0$ to .0$)$ & & \\
\hline \multicolumn{6}{|l|}{ Other Cytokines } \\
\hline IFN- $\gamma(\mathrm{pg} / \mathrm{ml})$ & & & & $.414, .036^{*}, .476$ & $1>3, p<.05$ \\
\hline placebo & $19.7(14.2)$ & $-6.2(-12.5$ to 0.1$)$ & $-9.2(-14.9$ to 3.5$)$ & & \\
\hline probiotic & $23.8(34.5)$ & $-8.1(-18.7$ to 2.5$)$ & $-6.3(-15.4$ to 2.8$)$ & & \\
\hline TNF- $\alpha$ (pg/ml) & & & & $.150, .002 *, .674$ & $\begin{array}{l}1>2, p<.05 \\
1>3, p<.001\end{array}$ \\
\hline placebo & $21.7(17.4)$ & $-4.1(-13.3$ to 5.1$)$ & $-11.6(-20.6$ to 2.6$)$ & & \\
\hline probiotic & $23.7(27.0)$ & $-14.1(-24.1$ to 4.1$)$ & $-13.0(-22.7$ to 3.3$)$ & & \\
\hline MCP-1 (pg/ml) & & & & $.391, .001 *, .878$ & $1>3, p<.001$ \\
\hline placebo & $778(155)$ & $-114(-145$ to 17$)$ & $-34(-153$ to 85$)$ & & \\
\hline probiotic & $820(69)$ & $-230(-346$ to 114$)$ & $-63(-143$ to 17$)$ & & \\
\hline
\end{tabular}

Note. IFN = interferon; TNF = tumor-necrosis factor; $\mathrm{MCP}=$ macrophage chemoattractant protein. Baseline values before supplementation are expressed as $M(S D) ; n=25$ probiotic, $n=20$ placebo. The values shown at 8 and 16 weeks of supplementation are the mean change (with $95 \%$ confidence limits) from baseline. These data are from the subjects who completed the study and for whom blood samples were obtained on all three visits. ${ }^{\mathrm{a}} 1=$ before $; 2=8$ weeks; $3=16$ weeks.

and nonathlete populations, falls in saliva IgA have been associated with increased infection incidence (Fahlman \& Engels, 2005; Gleeson et al., 1999; Neville et al., 2008). Alternatively, $\mathrm{LcS}$ supplementation could have caused an improvement in another aspect of immune function that we did not measure. In the current study we observed that antigen-stimulated whole-blood production of several cytokines decreased from baseline after 8 or 16 weeks of intervention with both probiotic and placebo treatments. It is not clear whether this observation represents a seasonal effect or an accumulation of training-stress effect.

A few recent probiotic intervention studies in athletes have provided evidence of apparent health benefit, with reports of fewer days of respiratory illness and lower 
severity of respiratory-illness symptoms (Cox et al., 2010; West, Pyne, Hopkins, et al., 2009) and shortened duration of GI-upset episodes (Kekkonen et al., 2007) when taking a daily Lactobacillus probiotic. Possible mechanisms appear to include higher spontaneous IFN- $\gamma$ production (Cox et al., 2010) and improved maintenance of salivary IgA levels (Tiollier et al., 2007) during periods of physical stress. West, Pyne, Hopkins, et al. (2009) recently reported that probiotic supplementation (L.fermentum) in a cohort of 64 male and 35 female elite endurance athletes was associated with a lower symptom load for chest infections and less use of cold and flu medications in males taking the probiotic compared with placebo, although differences in clinical outcomes between females in the two groups were not evident. In the current study there were more men than women in the cohort, and this may be another reason for the positive clinical outcome. In the current study there was no statistically significant difference in symptom severity or duration of URTI episodes with probiotic compared with placebo. However, this was not surprising given that we did not disallow oral medication when subjects experienced illness symptoms, and the proportion of subjects who took medication was similar in the probiotic and placebo groups (.74 and .78, respectively).

In summary, regular ingestion of LcS appears to be beneficial in preventing URTI in an athlete cohort, and training was less affected in the probiotic group when URTI was present. Regular ingestion of LcS also reduced the proportion of days that subjects suffered GI-discomfort symptoms. We could not directly attribute these health benefits to any specific alteration of systemic immune function because no substantial differences in any of the circulating immune variables measured were detected in probiotic compared with placebo, and there were no positive changes in the probiotic group at 8 or 16 weeks of intervention compared with Week 0 (baseline). The most likely possibilities are that $\mathrm{LcS}$ supplementation helped maintain saliva IgA concentration or had a positive impact on NK cell function.

\section{Acknowledgments}

This study was fully sponsored by Yakult Honsha Co., Ltd., Japan. Pedro Tauler received a José Castillejo grant from the Spanish Ministry of Science and Education. The results of the current study do not constitute endorsement of probiotics by the International Journal of Sport Nutrition and Exercise Metabolism.

\section{References}

Bishop, N.C. (2005). Exercise and infection risk. In M. Gleeson (Ed.), Immune function in sport and exercise (pp. 1-14). Edinburgh, UK: Elsevier.

Borchers, A.T., Selmi, C., Meyers, F.J., Keen, C.L., \& Gershwin, M.E. (2009). Probiotics and immunity. Journal of Gastroenterology, 44(1), 26-46.
Cohen, J.W. (1988). Statistical power analysis for the behavioral sciences (2nd ed., pp. 284-287). Hillsdale, NJ: Lawrence Erlbaum.

Collado, M.C., Isolauri, E., Salminen, S., \& Sanz, Y. (2009). The impact of probiotic on gut health. Current Drug Metabolism, 10(1), 68-78.

Cox, A.J., Pyne, D.B., Saunders, P.U., \& Fricker, P.A. (2010). Oral administration of the probiotic Lactobacillus fermentum VRI-003 and mucosal immunity in endurance athletes. British Journal of Sports Medicine, 44(4), 222-226.

Craig, C.L., Marshall, A.L., Sjostrom, M., Bauman, A.E., Booth, M.L., Ainsworth, B.E., . . O Oja, P. (2003). International physical activity questionnaire: 12-country reliability and validity. Medicine and Science in Sports and Exercise, 35(8), 1381-1395.

de Vrese, M., Winkler, P., Rautenberg, P., Harder, T., Noah, C., Laue, C., . . . Schrezenmeir, J. (2006). Probiotic bacteria reduced duration and severity but not the incidence of common cold episodes in a double blind, randomized, controlled trial. Vaccine, 24(44-46), 6670-6674.

Fahlman, M.M., \& Engels, H.J. (2005). Mucosal IgA and URTI in American college football players: A year longitudinal study. Medicine and Science in Sports and Exercise, 37(3), 374-380.

Fricker, P.A., Pyne, D.B., Saunders, P.U., Cox, A.J., Gleeson, M., \& Telford, R.D. (2005). Influence of training loads on patterns of illness in elite distance runners. Clinical Journal of Sport Medicine, 15(4), 246-252.

Gill, H., \& Prasad, J. (2008). Probiotics, immunomodulation, and health benefits. Advances in Experimental Medicine and Biology, 606, 423-454.

Gill, H.S., \& Cross, M.L. (2002). Probiotics and immune function. In P.C. Calder, C.J. Field, \& H.S. Gill (Eds.), Nutrition and immune function (pp. 251-272). Oxford, UK: CABI.

Gleeson, M. (Ed.). (2005). Immune function in sport and exercise. Edinburgh, UK: Elsevier.

Gleeson, M. (2007). Exercise and immune function. Journal of Applied Physiology, 103, 693-699.

Gleeson, M., McDonald, W.A., Pyne, D.B., Cripps, A.W., Francis, J.L., Fricker, P.A., \& Clancy, R.L. (1999). Salivary IgA levels and infection risk in elite swimmers. Medicine and Science in Sports and Exercise, 31, 67-73.

Guillemard, E., Tondu, F., Lacoin, F., \& Schrezenmeir, J. (2009). Consumption of a fermented dairy product containing the probiotic Lactobacillus casei $\mathrm{DN}-114001$ reduces the duration of respiratory infections in the elderly in a randomised controlled trial. The British Journal of Nutrition, 14, 1-11 (Epub ahead of print).

Hatakka, K., Savilahti, E., Ponka, A., Meurman, J.H., Poussa, T., Nase, L., . . Korpela, R. (2001). Effect of long term consumption of probiotic milk on infections in children attending day care centres: Double blind, randomised trial. British Journal of Medicine, 322(7298), 1327-1332.

Kekkonen, R.A., Vasankari, T.J., Vuorimaa, T., Haahtela, T., Julkunen, I., \& Korpela, R. (2007). The effect of probiotics on respiratory infections and gastrointestinal symptoms during training in marathon runners. International Journal of Sport Nutrition and Exercise Metabolism, 17(4), 352-383. 
Kim, H.S., Park, H., Cho, I.Y., Paik, H.D., \& Park, E. (2006). Dietary supplementation of probiotic Bacillus polyfermenticus, Bispan strain, modulates natural killer cell and $\mathrm{T}$ cell subset populations and immunoglobulin $\mathrm{G}$ levels in human subjects. Journal of Medicinal Food, 9(3), 321-327.

Kopp-Hoolihan, L. (2001). Prophylactic and therapeutic uses of probiotics: A review. Journal of the American Dietetic Association, 101(2), 229-238.

Kudsk, K.A. (2002). Current aspects of mucosal immunology and its influence by nutrition. American Journal of Surgery, 183(4), 390-398.

Lancaster, G.I., Halson, S.L., Khan, Q., Drysdale, P., Wallace, F., Jeukendrup, A.E., . . . Gleeson, M. (2004). Effects of acute exhaustive exercise and chronic exercise training on Type 1 and Type 2 lymphocytes. Exercise Immunology Review, 10, 91-106.

Matsumoto, K., Takada, T., Shimizu, K., Kado, Y., Kawakami, K., Makino, I., . . . Nomoto, K. (2006). The effects of a probiotic milk product containing Lactobacillus casei strain Shirota on the defecation frequency and the intestinal microflora of sub-optimal health state volunteers: A randomized placebocontrolled cross-over study. Bioscience Microflora, 25(2), 39-48.

Matsuzaki, T. (1998). Immunomodulation by treatment with Lactobacillus casei strain Shirota. International Journal of Food Microbiology, 41(2), 133-140.

Mengheri, E. (2008). Health, probiotics and inflammation. Journal of Clinical Gastroenterology, 42(2), S177-S178.

Miettinen, M., Vuopio-Varkila, J., \& Varkila, K. (1996). Production of human tumor necrosis factor alpha, interleukin-6, and interleukin-10 is induced by lactic acid bacteria. Infection and Immunity, 64(12), 5403-5405.

Minocha, A. (2009). Probiotics for preventive health. Nutrition in Clinical Practice, 24(2), 227-241.

Nagao, F., Nakayama, M., Muto, T., \& Okumura, K. (2000). Effects of a fermented milk drink containing Lactobacillus casei strain Shirota on the immune system in healthy human subjects. Bioscience, Biotechnology, and Biochemistry, 64(12), 2706-2708.

Neville, V., Gleeson, M., \& Folland, J.P. (2008). Salivary IgA as a risk factor for upper respiratory infections in elite professional athletes. Medicine and Science in Sports and Exercise, 40(7), 1228-1236.

Nieman, D.C., Johanssen, L.M., Lee, I.W., \& Arabatzis, K. (1990). Infectious episodes in runners before and after the Los Angeles Marathon. Journal of Sports Medicine and Physical Fitness, 30(3), 316-328.
O’Connell, E., Allgrove, J., Pollard, L., Xiang, M., \& Harbige, L.S. (2010). A pilot study investigating the effects of yakult fermented milk drink (L. casei Shirota) on salivary IFN-g, sIgA, IgA1 and IgA2 in healthy volunteers. Proceedings of the Nutrition Society, 69(OCE3), E267. doi:10.1017/ S002966511000056X

Olivares, M., Diaz-Ropero, M.P., Gomez, N., Lara-Villoslada, F., Sierra, S., Maldonado, J.A., . . Xaus, J. (2006). The consumption of two new probiotic strains, Lactobacillus gasseri CECT 5714 and Lactobacillus coryniformis CECT 5711 , boosts the immune system of healthy humans. International Microbiology, 9(1), 47-52.

Peters, E.M., \& Bateman, E.D. (1983). Ultramarathon running and URTI: An epidemiological survey. South African Medical Journal, 64(15), 582-584.

Pregliasco, F., Anselmi, G., Fonte, L., Giussani, F., Achieppati, S., \& Soletti, L. (2008). A new chance of preventing winter diseases by the administration of symbiotic formulations. Journal of Clinical Gastroenterology, 42(2), S224-S233.

Simons, S.M., \& Kennedy, R.G. (2004). Gastrointestinal problems in runners. Current Sports Medicine Reports, $3(2), 112-116$.

Spanhaak, S., Havenaar, R., \& Schaafsma, G. (1998). The effect of consumption of milk fermented by Lactobacillus casei strain Shirota on the intestinal microflora and immune parameters in humans. European Journal of Clinical Nutrition, 52(12), 899-907.

Tiollier, E., Chennaoui, M., Gomez-Marino, D., Drogou, C., Filaire, E., \& Guezennec, C.Y. (2007). Effect of a probiotic supplementation on respiratory infections and immune and hormonal parameters during intense military training. Military Medicine, 172(9), 1006-1011.

West, N.P., Pyne, D.B., Hopkins, W.G., Fricker, P.A., Jairath, A., Eskesen, D.C., \& Cripps, A.W. (2009). Probiotic supplementation, illness and immunity in athletes. In Proceedings of the 9th International Society of Exercise and Immunology Symposium (p. 63). Tubingen, Germany: International Society for Exercise and Immunology.

West, N.P., Pyne, D.B., Peake, J.M., \& Cripps, A.W. (2009). Probiotics, immunity and exercise: A review. Exercise Immunology Review, 15, 107-126.

Winkler, P., de Vrese, M., Laue, C., \& Schrezenmeir, J. (2005). Effect of a dietary supplement containing probiotic bacteria plus vitamins and minerals on common cold infections and cellular immune parameters. International Journal of Clinical Pharmacology, Therapy, and Toxicology, 43(7), 318-326. 